\title{
Measurement of serum C-reactive protein concentration in myocardial ischaemia and infarction
}

\author{
F C DE BEER, C R K HIND, K M FOX, R M ALLAN, A MASERI, M B PEPYS \\ From the Immunological Medicine and Cardiovascular Units, Department of Medicine, Royal Postgraduate Medical \\ School, Hammersmith Hospital, London
}

SUMMARY Serum C-reactive protein (CRP) and creatine kinase (CK) MB levels were measured prospectively in patients with definite myocardial infarction, patients with spontaneous or exerciseinduced angina, subjects undergoing coronary arteriography, and patients with non-cardiac chest pain. All individuals with infarction developed raised CRP levels and there was a significant correlation between the peak CRP and CK MB values. The CRP, however, peaked around 50 hours after the onset of pain at a time when the CK MB, which peaked after about 15 hours, had already returned to normal. In 20 patients who recovered uneventfully, CRP levels fell, returning to normal about seven days after infarction in four cases who were followed to this point. In eight complicated cases, including four who died within the first 10 days, the CRP level remained high. Angina alone or coronary arteriography did not cause a rise in the CRP or CK MB concentrations. Increased CRP production is a non-specific response to tissue injury and raised CRP levels in cases of chest pain with a normal CK MB indicated a pathological process other than myocardial infarction. Regular monitoring of CRP levels may also assist in early recognition of intercurrent complications occurring after myocardial infarction.

Differential diagnosis of myocardial infarction from other causes of chest pain is a common clinical problem. Even when the diagnosis is established there are many difficult questions such as: recognition of myocardial necrosis in patients with known ischaemic heart disease, recognition of intercurrent complications in the post-infarct period, prognosis in the immediate post-infarct period, and assessment of convalescent infarct patients for discharge from the coronary care unit to the ward, and from ward to home.

C-reactive protein (CRP) is the classical acute phase reactant, ' the serum level of which has long been known to increase after myocardial infarction. ${ }^{2-5}$ Earlier work, using relatively insensitive and semiquantitative assays, suggested that serial measurement of serum CRP levels may be useful in the diagnosis and management of myocardial infarction. ${ }^{2} 3$ We have reinvestigated this possibility in a prospective study of well-characterised patients using a precise quantitative assay for CRP, together with measurements of $\mathrm{CK} M B$, the specific myocardial isoenzyme of creatine kinase. ${ }^{6}$

Accepted for publication 24 November 1981

\section{Patients and methods}

The following groups of patients were studied: 33 with definite myocardial infarction on clinical grounds confirmed by electrocardiogram and a rise in CK MB level, seven with severe angina admitted to the coronary care unit with suspicion of infarction but no increase in $\mathrm{CK} \mathrm{MB}, 12$ undergoing exercise testing for known or suspected myocardial ischaemia, 11 undergoing coronary arteriography, and five with chest pain of non-cardiac origin. Venous blood samples were obtained from the patients with infarcts or spontaneous angina on admission, then at two to four hour intervals for the first 24 to 48 hours, and subsequently at eight to 12 hour intervals for the next one to four days in 34 patients and up to 10 days in six patients. The patients in other groups were bled before and 24 and 48 hours after exercise testing or arteriography. Serum was separated after clotting for one hour at room temperature and frozen promptly at $-20^{\circ} \mathrm{C}$. Samples were thawed once only and run in batches to determine the concentration of CRP using a new rapid immunoradiometric assay, ${ }^{7}$ and of CK MB using assay kits (EM Diagnostics Ltd, Greenford, Middlesex). The CRP assay provides results on up to 50 
samples in one hour with intra- and inter-assay coefficients of variation of 5 to $10 \% .^{7}$ Among normal healthy subjects $90 \%$ have serum CRP levels less than $3 \mathrm{mg} / \mathrm{l}$ and $99 \%$ are less than $10 \mathrm{mg} / .^{8}$

\section{Results}

SERUM CRP AND CK MB LEVELS IN PATIENTS WITH DEFINITE MYOCARDIAL INFARCTION

All patients with definite myocardial infarction mounted a CRP response and there was a statistically significant correlation between the peak levels of CRP and of CK MB (Fig. 1, Kendall's rank correlation coefficient $\tau=0.441, \mathrm{p}<0.001)$. Two individuals had relatively modest peak CRP levels. One was a 74year-old woman in whom temporal arteritis had been diagnosed one year previously and who was on daily prednisolone therapy. The other was a 40-year-old Negro from the West Indies who had no known antecedent disease or treatment. The peak level of CRP occurred later after the onset of pain than did the peak level of $C K M B$, the mean $\pm S D$ time to peak being $50.5 \pm 23.3$ hours for CRP and 14.8 \pm 8.6 hours for CK MB. In 20 uncomplicated cases who made a good recovery the CRP concentration fell from its peak within 12 to 24 hours and in four patients who were followed for a sufficient period, it remained at low levels thereafter. In eight cases, however, in whom progress during the immediate post-infarct period was interrupted by cardiac insufficiency resulting from arrhythmias or a low output state the CRP concentration did not return to normal. Four patients who died within the first 10 days all had persistently high or rising CRP levels at the time of death. These

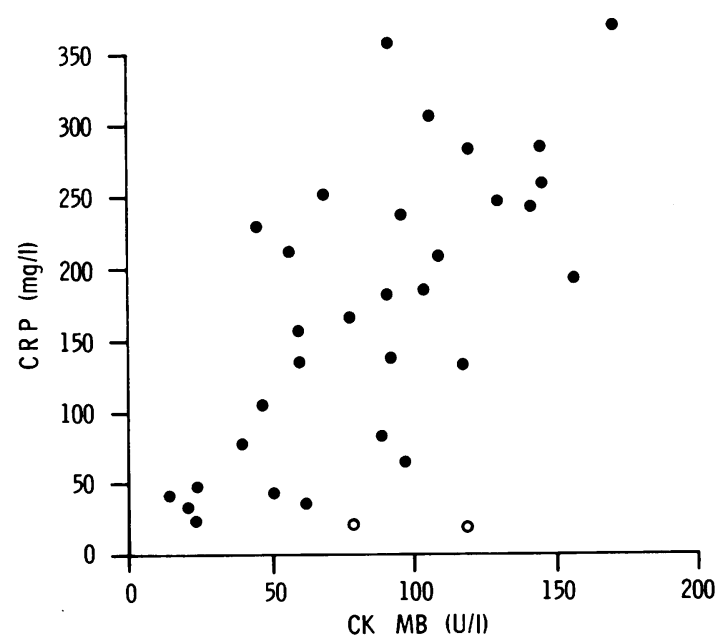

Fig. 1 Peak serum levels of $C R P$ and $C K M B$ in myocardial infarction. The two individuals with relatively poor $C R P$ response are indicated $(\mathrm{O})$. observations are illustrated by the cases shown in Fig. 2 and 3.

\section{SERUM CRP LEVELS IN ANGINA AND AFTER}

CORONARY ARTERIOGRAPHY

Among the 12 patients who were studied in relation to exercise testing, six experienced anginal pain during the test and three showed ST segment changes in their electrocardiograms. None showed any rise of either CRP or CK MB. Seven patients with severe chest pain were admitted to the coronary care unit for observation; two of them had crescendo angina. None showed a rise in CK MB though three had modestly raised CRP levels on admission. In only one of these patients did the CRP subsequently increase in concentration, reaching $29 \mathrm{mg} / \mathrm{l}$, and this was a woman of 60 years in whom the original diagnosis of myocardial infarction was revised to pulmonary embolism. She died suddenly but no necropsy was performed. Among the 11 patients undergoing coronary arteriography, lesions were shown in the coronary arteries of eight. The CK $M B$ level did not rise in any case and the CRP rose in only one, from $<1 \mathrm{mg} / \mathrm{l}$ to $24 \mathrm{mg} / \mathrm{l}$ in a subject with normal coronary arteries. Clinical events which occurred during catheterisation but which were not associated with increases in either CK MB or CRP included: an episode of ventricular tachycardia lasting 30 seconds, three episodes of chest pain in three patients, one episode of hypotension, and ST segment/ $\mathrm{T}$ wave changes in two patients.

\section{SERUM CRP LEVELS IN PATIENTS WITH CHEST} PAIN NOT CAUSED BY MYOCARDIAL INFARCTION Raised CRP concentrations occurred in patients with pulmonary embolism, pneumothorax, and severe chest pain of unknown cause (see below). Furthermore, intercurrent infection or thrombotic complications in patients with angina or after infarction were associated with increased CRP production but no rise in CK MB. This situation is exemplified by the case illustrated in Fig. 4, a man of 60 years known to have ischaemic heart disease. After an episode of angina one month previously he was admitted to the coronary care unit with an episode of severe chest pain. Intra- $\tilde{N}$ venous and intra-arterial lines were inserted for monitoring and the electrocardiogram was compatible $\mathcal{N}$ with subendocardial ischaemia. There was no rise of $\omega$ CK MB and the CRP was also initially normal, but about 24 hours after admission it began to rise slowly. After 60 hours he became febrile and then confused $\mathbb{\Phi}$ but no cause of these symptoms was demonstrable? either on clinical or direct microbiological examina- $\frac{T}{\circ}$ tion. During this time his serum CRP had climbed $\stackrel{\vec{D}}{\circ}$ rapidly to a very high level. Blood and other cultures $\frac{?}{\Phi}$ were taken, the intravascular lines removed, and the $\stackrel{2}{2}$ broad spectrum antibiotics begun. Over the next 48 웅 


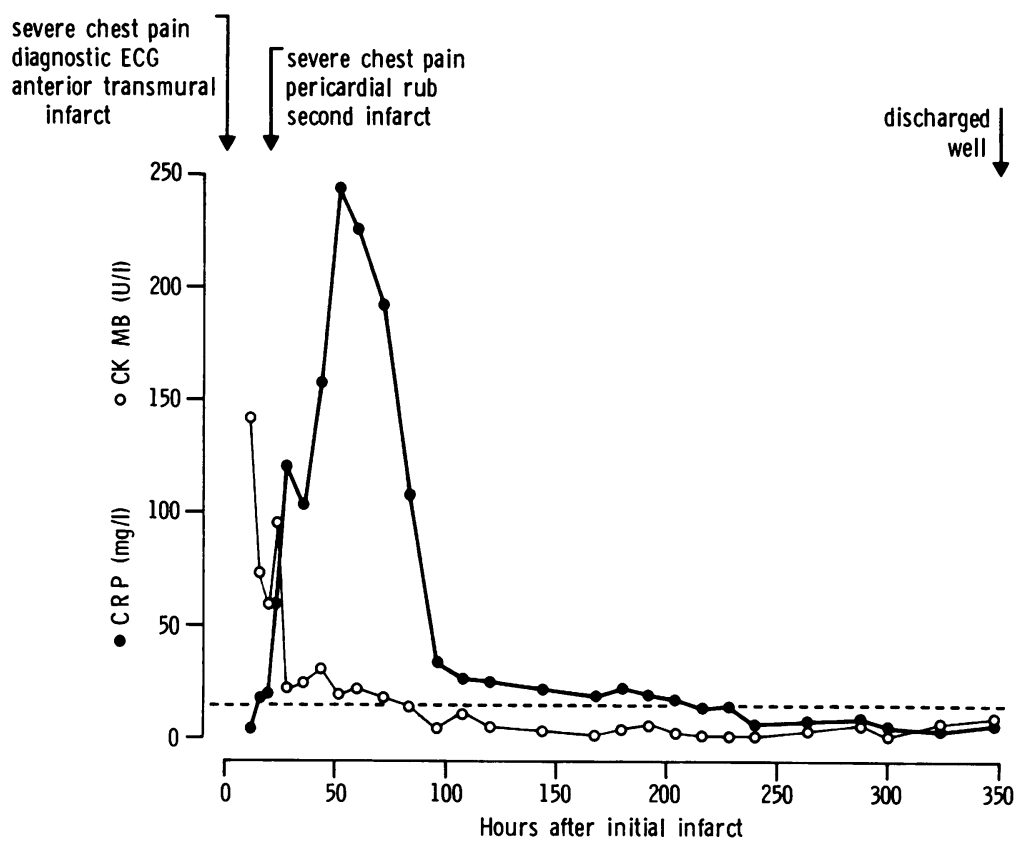

Fig. 2 Serial $C R P$ and $C K M B$ values in a 52-year-old man who suffered two episodes of myocardial infarction in rapid succession but then made an uneventful recovery. ---, upper limit of normal for $C K M B$.

severe chest pain

diagnostic ECG

inferior infarct

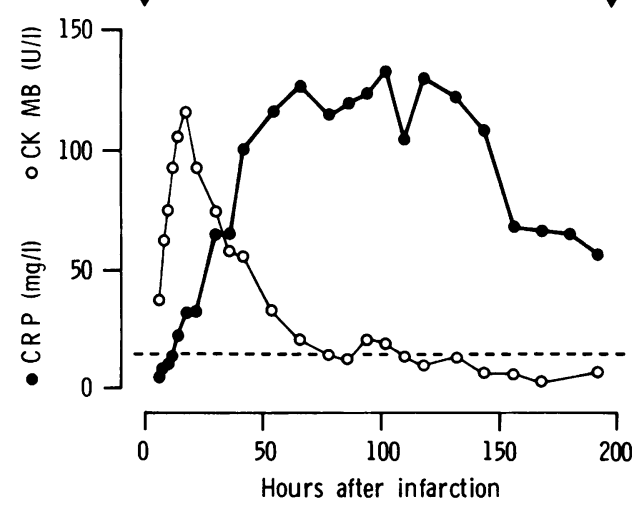

Fig. 3 Serial CRP and CK MB values in a 50-year-old man who had previously recovered from an anterior myocardial infarct but then suffered fresh inferior infarction. He remained unwell thereafter with a low output state and died 200 hours after the onset of pain. - - -, upper limit of normal for $C K M B$.

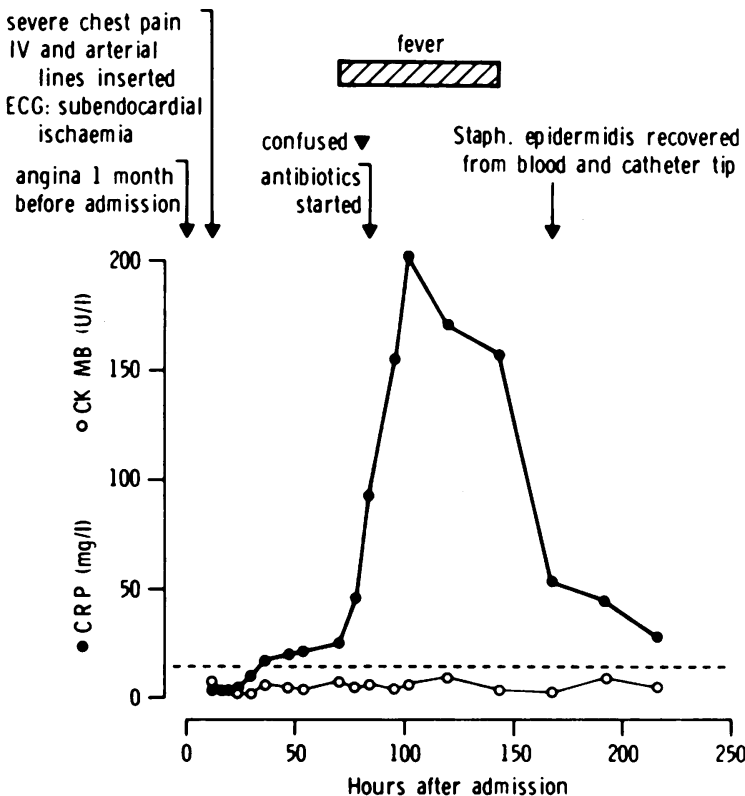

Fig. 4 Serial $C R P$ and $C K M B$ values in a 60-year-old man with known ischaemic heart disease after acute admission to the coronary care unit with severe chest pain. There was no evidence of infarction but he suffered a septicaemic illness associated with the presence of intravascular lines. - - -, upper limit of normal for $C K M B$. 
hours he improved and became afebrile, the CRP falling promptly towards normal, and he made an uneventful recovery. Staph. epidermidis was subsequently grown from the blood and the catheter tip obtained before starting antibiotics.

Another example of the potential value of regular, frequent, and rapid monitoring of CRP is provided by the case of a 37-year-old Indian man who was admitted to hospital with a clinical diagnosis of crescendo angina. The chest radiograph was normal but the electrocardiogram showed slight left ventricular hypertrophy. Over the next $\mathbf{4 2}$ hours there was no rise in $\mathrm{CK} \mathrm{MB}$, aspartate aminotransferase, or any other routinely measured biochemical variable. A slight fever developed but the pain abated and the patient insisted on discharging himself. He experienced further pain at home during the next few days but refused to be readmitted and he died five days later. Necropsy was refused so the causes of his pain and demise are unknown. Subsequent assay of his serum CRP, however, showed that it rose from a normal value of $2 \mathrm{mg} / \mathrm{l}$ on admission to $42 \mathrm{mg} / 1$ at 17 hours, $70 \mathrm{mg} / 1$ at 28 hours, and $76 \mathrm{mg} / 1$ at 42 hours. These high levels indicate unequivocally the onset and progression of a tissue-damaging organic disease process and if available at the time might have assisted in the patient's management or at least facilitated his continued stay in hospital.

\section{Discussion}

Increased CRP production is a non-specific response to most forms of cell death, tissue injury, infection, or inflammation, and it is clear that myocardial necrosis is a potent stimulus. All the patients studied here in whom there was a significant rise in $\mathrm{CK} M B$ also showed a rise in CRP concentration, and though this was relatively modest in two cases (one of whom was on steroids), there was a significant correlation between the peak values attained by these two completely distinct variables. Similar results have recently been reported in abstract form by Catheline et al.$^{9}$ Occurrence of the peak level of CRP at a mean time of 50 hours after the onset of pain compared with the peak of CK MB at about 15 hours suggests that measurement of CRP may be useful in cases in which the diagnosis of infarction is only suspected late, or which are only seen for investigation at a time when CK MB has returned to normal.

Cases of spontaneous or induced angina or individuals undergoing coronary arteriography generally did not show an increase of CRP in the absence of a rise in CK MB. Precise sequential measurements of CRP may thus serve as a sensitive test for myocardial necrosis in the context of ischaemic heart disease.

A rise in CRP in cases of chest pain without raised
CK MB strongly suggests a non-infarctive or noncardiac lesion and may assist in diagnosis of the cause of pain or in early recognition of intercurrent complications in cases of angina or after infarction. For example, if the CRP results in the case illustrated in Fig. 4 had been available at the time rather than after the event, cultures could have been taken before the onset of fever or other symptoms, his intravascular catheters changed, and prophylactic antibiotics begun much earlier. Assay of CRP may also provide an objective criterion to assist in decisions regarding suitability of individual patients for transfer from the coronary care unit to the ward or from the ward to home. On all these grounds we suggest that, provided the results are interpreted in the light of detailed knowledge of the patients' clinical condition and in conjunction with $\mathrm{CK} M B$ values, regular assay of CRP may play a valuable part in differential diagnosis of the chest pain syndrome. and in management of individuals with known or suspected myocardial ischaemia or infarction.

We thank the MRC (Programme grant to MBP) for support, and Dr Dennis Krikler for helpful advice and for permission to study patients under his care. The kits for measuring $\mathrm{CK} \mathrm{MB}$ were kindly provided by EM Diagnostics Ltd, Greenford, Middlesex.

\section{References}

1 Pepys MB. C-reactive protein fifty years on. Lancet 1981; i: 653-6.

2 Kroop IG, Shackman NH. The C-reactive protein determination as an index of myocardial necrosis in coronary artery disease. Am $\mathcal{F}$ Med 1957; 22: 90-8.

3 Levinger EL, Levy H, Elster SK. Study of C-reactive protein in the sera of patients with acute myocardial infarction. Ann Intern Med 1957; 46: 68-78.

4 Kushner I, Broder ML, Karp D. Control of the acute phase response. Serum C-reactive protein kinetics after acute myocardial infarction. $\mathcal{F}$ Clin Invest 1978; 61: 23542.

5 Johansson BG, Kindmark C-O, Trell EY, Wollheim FA. Sequential changes of plasma proteins after myocardial infarction. Scand f Clin Lab Invest 1972; 29, suppl 124: 117-26.

6 Rogers WJ, McDaniel HG, Smith LR, Mantle JA, Russell RO Jr, Rackley CE. Correlation of angiographic estimates of myocardial infarct size and accumulated release of creatine kinase MB isoenzyme in man. Circulation 1977; 56: 199-205.

7 de Beer FC, Pepys MB. Solid phase immunoradiometric assay for C-reactive protein using magnetisable cellulose particles. I Immunol Methods 1982; in press.

8 Shine B, de Beer FC, Pepys MB. Solid phase radioimmunoassays for C-reactive protein. Clin Chim Acta 1981; 117: 13-23. 
9 Catheline M, Bouget J, Delbary M, Couliou H. Dosage de la C. réactive protéine sérique. Elément supplémentaire de diagnostic et d'appréciation de l'importance de la nécrose myocardique. Nouv Presse Med 1980; 9: 3092-4.
Requests for reprints to Dr M B Pepys, Immunological Medicine Unit, Department of Medicine, Royal Postgraduate Medical School, Hammersmith Hospital, Du Cane Road, London W12 0HS. 